This document is published in:

Small Business Economics (2004), 22 (3-4), pp. 193-207.

Doi: http://www.dx.doi.org/10.1023/B:SBEJ.0000022220.07366.b5

(C) 2004 Kluwer Academic Publishers 


\section{How Does Probability of Innovation Change with Firm Age?}

Elena Huergo

Jordi Jaumandreu

\begin{abstract}
This paper looks at the probability of introducing innovations by manufacturing firms at different stages of their lives. Once differences related to activity and size are controlled for, we examine how the probability of innovation varies over entry, post-entry ages, and advanced ages of mature firms. We also measure the association between exit from the market and pre-exit innovation. Results show that the probability of innovating widely varies by activity, and that small size per se broadly reduces the probability of innovation, but also that entrant firms tend to present the highest probability of innovation while the oldest firms tend to show lower innovative probabilities. Some sets of firms with intermediate ages also present a high probability of innovation, and exiting firms are clearly associated to lower levels of introducing process innovations.
\end{abstract}

\section{Introduction}

Looking at the probability of introducing innovations according to age is likely to shed light on the dynamics of industries. Industries' technology and products evolve according to the innovations introduced by the entrants, surviving and incumbent firms, and these innovations are one of the main sources of industry growth and changes in its structure. A few papers have developed theoret-

Elena Huergo

Universidad Complutense de Madrid

Dpto. Fundamentos del Análisis Económico I

Facultad de Ciencias Económicas y Empresariales

Campus de Somosaguas

28223 Madrid

Spain

E-mail: ehuergo@ccee.ucm.es

Jordi Jaumandreu

Universidad Carlos III de Madrid

Dpto. Economía. Facultad de Ciencias Sociales y Jurídicas C/Madrid 126

28903 Getafe

Spain

E-mail: jordij@eco.uc3m.es ical insights into the nature of these dynamics (Audretsch (1995b), Klepper (1996)), while many others contain pieces of evidence on the innovative behaviour of firms according to their time in the market (see Section 2).

To contribute to this literature, this paper looks at the probability of introducing innovations by manufacturing firms at different stages of their lives. To analyse the evolution of this probability with age, differences in probability levels across activities must firstly be controlled for, as well as the size of firms. Small size is in general terms likely to hamper innovative activities, but newly born firms are typically small and very innovative, and we want to separate the effects of entry from the effects of size. Once differences related to activity and size are controlled, we examine how the probability of innovating varies over entry, post-entry ages, and advanced ages of mature firms. We also measure the association between exit from the market and pre-exit innovation. By using a semiparametric specification of a linear probability model, the empirical estimation is able to calculate the impact of age without imposing any functional form a priori.

To assess the relationship between the probability of innovation and age, we use an unbalanced panel data sample which is representative of Spanish manufacturing, including more than 2,300 firms. The data include entrants, exiting and continuing companies, and shows a high heterogeneity in the degree to which they undertake innovative activities. Firms are observed from 1991 to 1998, and they report yearly if they have introduced process and product innovations. The process innovations reported by firms have already been successfully related to contemporaneous total factor productivity jumps and some persistent productivity growth effects in Huergo and Jaumandreu (2002). 
Results show that the probability of innovating widely varies by activity, and that small size per se greatly reduces the probability of innovation. But they also show that entrant firms tend to present the highest probability of innovation, while the oldest firms show lower innovative probabilities. However, some sets of firms with intermediate ages also present a high probability of innovation, and exiting firms are clearly associated with lower levels of introducing process innovations. On the whole, the relative innovative behaviour of entrants, surviving and old incumbents depicts a sensible framework, perfectly consistent with industries with a high turnover, based on the results of innovation and growth.

The rest of the paper is organised as follows. Section Two summarises the relationships which can be expected between innovation and age of the firms. Section Three briefly presents the probability model. Section Four details the data and variable definitions, and mentions some facts about innovation in Spanish manufacturing during the nineties. Section Five presents the empirical results and Section Six concludes. An Appendix provides some details on the model and the estimation technique.

\section{Innovation and firms' age}

Looking at the probability of introducing innovations according to the age of the firms makes sense because it provides us with insights into a key aspect of the dynamics of industries. Empirical research on industry evolution has recently shown that industries' entry and exit are typically high, that new firms start on a very small scale but also that they are not able to remain small forever, and that survival depends on heterogeneous mechanisms which include crucial innovation and growth (see, for example, Audretsch (1995a)). Accordingly, scholars have shifted the emphasis from the role of entry as an industry's disciplinary device to its envisioning as a fundamental mechanism of industry evolution (see, for example, Geroski (1995)). Industries' technology and products evolve according to the innovations introduced by the entrants, the innovations of the surviving and incumbent firms and, in summary, according to the relative innovative roles played by the different cohorts which conform a market at a given date. These innovations are one of the main sources of industry growth and changes in its structure.

What regularities can be expected from relative innovation? A general framework for the relationships among entry, post-entry growth, the incumbents' role and innovation can be found, for example, in Audretsch (1995b). Entry is envisaged as the way in which firms explore the value of new ideas in an uncertain context, typically starting at a modest scale. Entry, the likelihood of survival and subsequent conditional growth are determined by barriers to survival, which may greatly differ by industries according to technological opportunities (and scale economies). Innovative advantages of entering firms, for example, are likely to differ according to the degree to which the technological regime is "entrepreneurial" or "routinised", which in turn depends on the degree to which knowledge is based on "non-transferable" experience.

In this framework, entry is innovative and increases with uncertainty, the likelihood of survival is lower the higher the risk is, and the growth subsequent to successful innovation is higher, the higher barriers to survival are. The model is not completely explicit about the propensity to innovate, and it mainly allows for explaining the presence of significant differences between industries (one of the framework's aims), according to their technological opportunities. But it clearly suggests that we must find the highest innovators of a given industry among the entrant firms and, if growth is linked to subsequent innovation, also among the successful surviving firms.

Formal predictions about how innovation can be expected to evolve as an industry develops are found in Klepper (1996). The industry model formally obtains a series of regularities which mimic the characteristics usually described for the "product life cycle" of industries. It depicts the entry and stay decisions of, respectively, potential entrants and incumbents, as well as their product and process $\mathrm{R} \& \mathrm{D}$ spending to improve or produce more efficiently the standard product of the industry (sold at a market clearing price). Innovation is proportional to spending, product innovation gives the innovator transitory power over a group of new buyers and process innova- 
tion reduces cost. Changing market shares by other methods is costly and hence firms have incentives to innovate. The incentive to reduce product unit cost is higher the greater firm size is.

The model has three main predictions concerning innovation. Firstly, the total number of product innovations will eventually decrease over time. Secondly, as time goes by, firms that remain in the market increase the relative $R \& D$ effort aimed at developing process innovations. Thirdly, the number of innovations per firm at a given moment of time will be higher the newer the cohort is (industry entrants tend to account for a disproportionate share of product innovations relative to incumbents). Another model implication is that productivity of $R \& D$ spending decreases with size (a consequence of higher spending at diminishing returns). According to the third proposition, the model clearly predicts an inverse relationship between age and propensity to innovate at the industry level. But a serious difficulty must be noticed here when comparing firms belonging to different markets, even if the activities' innovation differences are accounted for. Age must be assumed to be relative age, measured in relation to an unobservable total length of the specific "product life cycle," and these lengths may widely differ.

The existing evidence on innovation and age presents different entities according to the agetopics involved, and direct evidence relating the propensity to innovate to age for all relevant firms is scarce. The link between entry and innovation is well documented. The papers by Acs and Audretsch (1988, 1990), among others, clearly manifest the importance of innovation by smallentrant firms. And Hansen (1992), for example, finds in a sample of American firms that the number of new products by unit of sales and the proportion of innovative sales are inversely related to firm age.

The relationship between survival and innovative performance is however, although broadly accepted, less documented. Audretsch (1995b) finds evidence of an improved likelihood of survival after surviving the few years subsequent to entry. Doms et al. (1995), for example, show that adoption of advanced technology by American manufacturing plants (which is different from, but presumably related to, process innova- tion) makes them less likely to fail. Somewhat more directly, Agarwal (1998) relates small firms' survival to innovative performance.

Finally, evidence on innovation by advancedage firms is more scarce. Cohen and Klepper (1996) argue that firm size is likely to condition the composition of $\mathrm{R} \& \mathrm{D}$ expenditure towards process innovation activities, and they obtain evidence of a positive relationship between size and process innovation with American business level data. McGahan and Silverman (2001), using patenting data, conclude for a sample of industries that there is no evidence that leaders innovate less in mature industries, and that patenting activity is not lower in such industries.

Using an interindustry sample which covers the whole existing age distribution, this paper aims to make a contribution to the assessment of the relationship between innovation and age. According to the theoretical insights, some negative relationship should be found within industries, although there are also theoretical reasons to expect some abnormalities (innovation by successful growing survivors, aged firms of "routinised" sectors ....). The same theoretical insights, by stressing the importance of industry differences, also point out that approximating the right average propensity-to-innovate/age relationship within industries implies crucial controlling for the heterogeneity of the average propensity to innovate across markets.

\section{The model}

To link the probability of introducing process innovations to age we will, using all the crosssection and time observations available, estimate the following probability model

$$
P\left(y_{i t}=1 \mid x, \tau\right)=E\left(y_{i t} \mid x, \tau\right)=x_{i t} \beta+\theta\left(\tau_{i t}\right)
$$

where $y$ is a $0 / 1$ variable that takes value 1 when firm $i$ reports introducing a process innovation, $x$ represents the vector of control variables (dummies of activity, size and others), $\tau_{i t}$ represents the age of the $i$-th firm at time $t$ and $\theta(\cdot)$ stands for the unknown function linking probability to firm age. One important variable to be included in $x$ is a dummy characterising all the firms that are seen exiting the market. Equation (1) represents a semiparametric regression model 
of the type studied by Speckman (1988) and Robinson (1988), among others. Details on the model and the estimation technique are given in the Appendix.

The main advantage of such a specification is that we are not imposing any a priori constraint on the function which links the probability of innovation to age. This is especially suitable given that we can presume a highly non-linear relationship whose form we can hardly guess. In order to have a good estimate, however, it is crucial to control properly for any heterogeneity in which we want to condition this relationship (this is accomplished by the controls which enter the equation linearly). It must be borne in mind, however, that our equation is not an explanation of the probability of innovation in terms of sundry variables. We want to grasp the relation innovation/time in the market, whichever variables (more or less related to the time in the market) explain the introduction of innovations.

Specification (1) uses the linear probability model. An important advantage of this model is that we can directly interpret all dummy coefficients, and the own values of the unknown function, giving percentage points that add up to total probability. ${ }^{1}$ The unknown function of (1) includes the constant of the regression, and hence dummy coefficients must be estimated as differences from the value of the function. This is accomplished by means of the Suits method, constraining the sets of dummy coefficients to add up to zero (see Suits (1984)).

\section{The data}

Estimations are carried out with data on more than 2,300 firms, including newborn, continuing and exiting firms, observed during the period 19911998. The sample period hence covers an almost complete industrial cycle, ranging from the end of a boom of the Spanish economy (1991) to the next recovery (1994-1998), including the short strong downturn which peaked in 1993 and the economic growth pause of 1995-1996 (see Figure 1).

The sample constitutes an unbalanced panel data set, whose composition in terms of observations per firm can be checked in Table I. The panel includes 582 firms with information available for the complete period 1991 to 1998 (8 time observations), but also firms observed for shorter time spells (from 7 to 1 time observations). The third column of the table gives the total available number of observations for each group of firms (the product between numbers in columns 1 and 2 ). The sample comes from the official survey

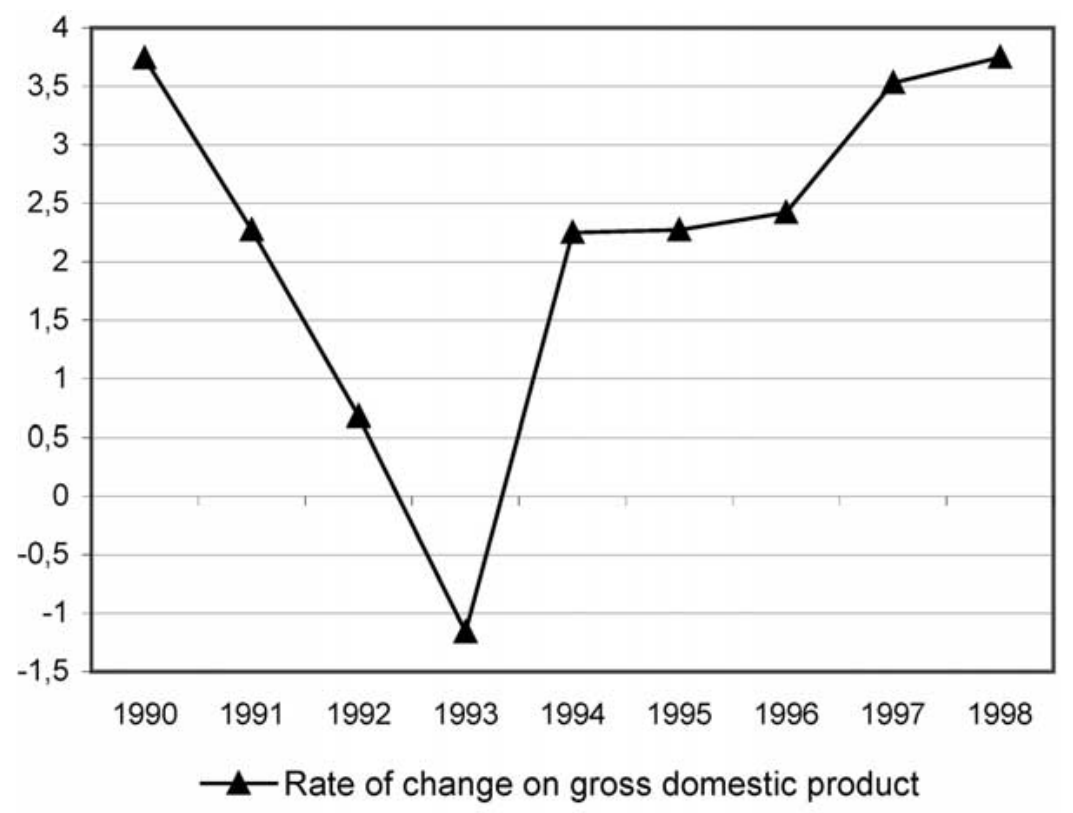

Figure 1. Spanish business cycle. 
TABLE I

Number of firms, time observations and frequency of process and product innovation

\begin{tabular}{lccll}
\hline Time observations & No. of firms & No. of observations & \% of process innovations & \% of product innovations \\
\hline 1 & 393 & 393 & 33.8 & 25.5 \\
2 & 353 & 706 & 31.6 & 24.8 \\
3 & 221 & 663 & 30.6 & 25.6 \\
4 & 278 & 1,112 & 31.1 & 27.1 \\
5 & 159 & 795 & 37.9 & 29.4 \\
6 & 180 & 1,080 & 30.2 & 24.4 \\
7 & 190 & 1,330 & 35.3 & 29.0 \\
8 & 582 & 4,656 & 38.2 & 26.5 \\
Total & & & 34.0 & \\
\hline
\end{tabular}

"Encuesta sobre Estrategias Empresariales" $(\mathrm{ESEE})^{2}$ from which we have dropped those observations lacking the data needed to perform the exercise. It is approximately representative of manufacturing firms with more than 10 workers ${ }^{3}$ hence, inferences can be considered globally valid for Spanish manufacturing (see below).

The composition of the sample is as follows. At the beginning of the period, firms with fewer than 200 workers were sampled randomly by industry and size strata, retaining about $5 \%$, while firms with more than 200 workers were all requested to participate, and the positive answers represented a self-selected $68 \%$ of firms within this size. ${ }^{4}$ Table II details the ESEE initial sample as a proportion of manufacturing population numbers of firms (with more than 10 workers). To preserve representation, samples of newly created firms were added to the initial sample every subsequent year. At the same time, there are exits from the sample, coming both from death and attrition. The two motives can be distinguished and attrition was maintained under sensible limits. We will estimate a separate probability level for the firms exiting by death by means of a dummy that takes the value 1 for every one of their time observations.

Information covered by the survey allows us to know the firms' age and the years they introduce process and product innovations. In addition, we know firms' activity from a standard breakdown of manufacturing in industries and firms' size in terms of the total number of workers. In what follows, we detail the contents of the main variables and give some descriptive statistics.

The variable age is computed from the difference between the current year and the constituent year reported by the firm; when this difference is higher than 40 years it is changed to a unique category of 40 years or more (this is the maximum life span with economic meaning to Spanish manufacturing circa 1998). The age distribution, given the character of the sample, is expected to be representative of the age distribution of the two manufacturing subpopulations considered (firms with 200 or fewer workers and firms with more than 200 workers). Figure 2 depicts the histogram of sample ages. Notice its bimodal character after grouping values at 40 years.

A process innovation is assumed to have occurred when the firm answers positively to the following request: "Please indicate if during the year 199x your firm introduced some significant modification in the production process (process innovation). If the answer is yes, please indicate the way: (a) introduction of new machines; (b) introduction of new methods of organisation; (c) both."

A number of observations and comments are in order. Firstly, the question appears in the questionnaire along with the other R\&D and innovation-related questions and, particularly, after all the questions about incurred expenditures and product innovations. Secondly, the questionnaire contains other sections on advanced technology adoption and usage which facilitate their distinction from process innovations. Hence, the question provides an interesting measure of the frequency with which firms obtain substantial changes in their production process through innovative activity. In addition, the question is an inquiry on the innovative output reported by each firm, which avoids the well-known reporting problems derived 
TABLE II

Sample coverage by size and industry strata (percentages)

\begin{tabular}{|c|c|c|c|c|c|}
\hline & \multicolumn{5}{|c|}{ No. of workers } \\
\hline & Up to 20 & From 21 to 50 & From 51 to 100 & From 101 to 199 & More than 200 \\
\hline Ferrous and non-ferrous metals & 4.3 & 5.4 & 4.7 & 5.0 & 73.9 \\
\hline Non-metallic mineral products & 3.9 & 4.3 & 4.8 & 4.5 & 61.1 \\
\hline Chemical products & 4.9 & 4.4 & 5.3 & 5.1 & 68.2 \\
\hline Metal products & 1.6 & 3.1 & 4.3 & 5.0 & 71.3 \\
\hline Industrial and agricultural mach. & 4.3 & 3.8 & 4.0 & 9.3 & 76.1 \\
\hline Office and data processing $\mathrm{m}$. & 12.1 & 10.0 & 37.5 & - & 100.0 \\
\hline Electrical goods & 4.3 & 4.6 & 4.5 & 9.3 & 68.7 \\
\hline Electronic goods & 4.4 & 5.3 & 6.7 & 26.7 & 76.2 \\
\hline Vehicles, cars and motors & 5.8 & 4.3 & 4.7 & 5.6 & 71.1 \\
\hline Shipbuilding & 3.2 & 8.4 & 18.2 & 37.5 & 75.0 \\
\hline Other transport equipment & 7.5 & 8.0 & 21.7 & 27.8 & 78.6 \\
\hline Precision instruments and optics & 4.8 & 6.5 & 7.6 & 15.0 & 76.5 \\
\hline Food & 4.5 & 4.7 & 4.8 & 4.0 & 63.7 \\
\hline Beverages and tobacco & 5.0 & 5.1 & 6.8 & 2.5 & 60.2 \\
\hline Textile & 4.3 & 3.9 & 3.7 & 6.2 & 56.9 \\
\hline Leather & 4.6 & 4.8 & 7.0 & 14.3 & 88.9 \\
\hline Shoes and clothing & 3.1 & 4.0 & 4.0 & 6.8 & 79.5 \\
\hline Timber and furniture & 2.7 & 4.7 & 4.8 & 7.4 & 62.5 \\
\hline Paper and printing products & 4.2 & 3.9 & 3.7 & 5.0 & 64.6 \\
\hline Rubber and plastic products & 3.2 & 3.7 & 1.9 & 3.9 & 73.3 \\
\hline Other manufacturing products & 5.2 & 6.3 & 10.5 & 36.4 & 77.8 \\
\hline Total manufacturing & 3.5 & 4.2 & 4.8 & 6.3 & 68.1 \\
\hline
\end{tabular}

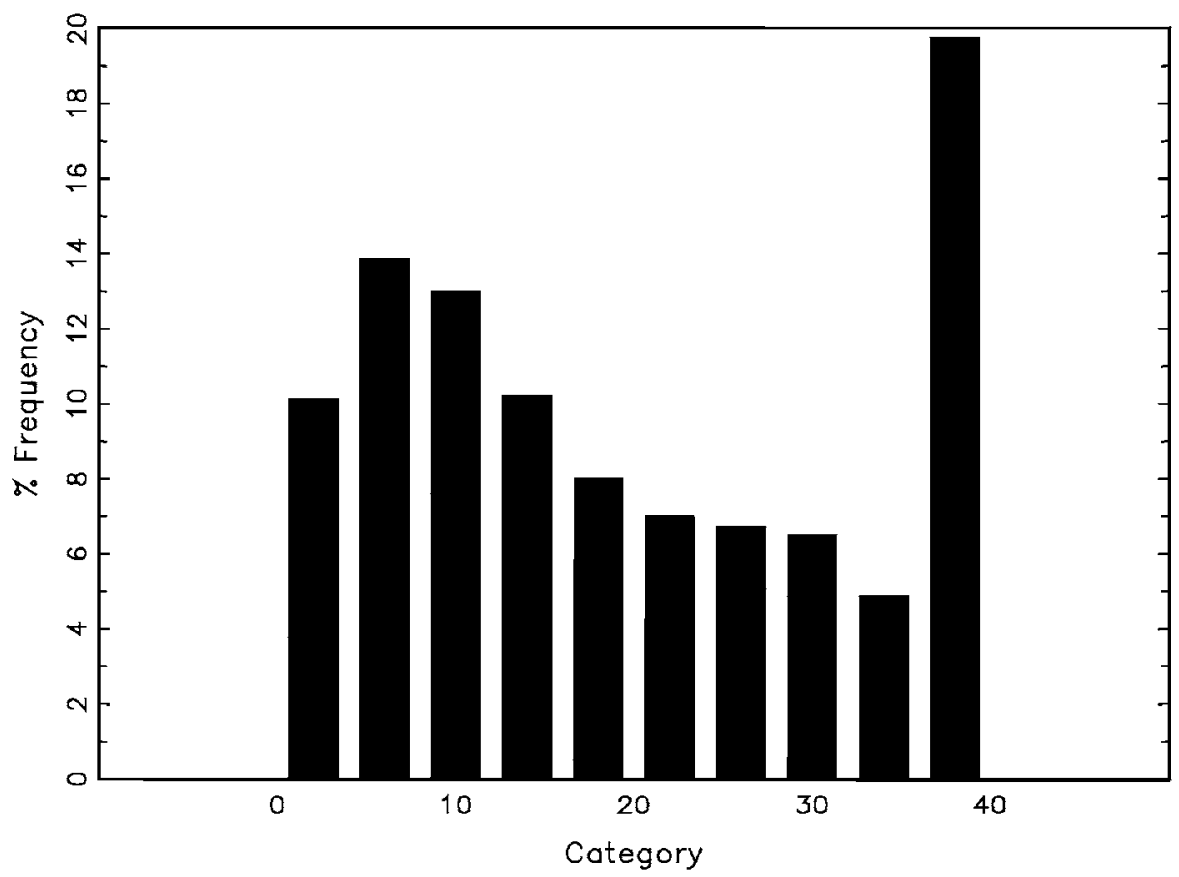

Figure 2. The histogram of age. 
from the difference between formal and informal innovative activities. As far as the practical performance of the measure is concerned, Huergo and Jaumandreu (2002) show the link of these observations to firms' total factor productivity growth the same year and the subsequent three years.

A product innovation is assumed to have occurred when the firm answers in the affirmative to the following request: "Please indicate if during the year 199x your firm has obtained product innovations (completely new products or products with such important modifications which made them different from the old ones). If the answer is yes, please indicate the number of innovations and the kind of embodied novelty: (a) new materials; (b) new components; (c) new design and (d) new functionality."

Table I reports the frequency with which firms introduce process and product innovations. The columns "\% of innovations" are constructed in the following way: for each firm in the sample we compute the proportion of time observations in which they report innovations, then we average these proportions for each group of firms. The table shows that these proportions are independent of the number of years we observe the firms and amount roughly to one third and one fourth of the years.

\section{Empirical results}

This section reports the results of the estimation of probability model (1) alternatively using the firms' process and product innovation information. The model is first estimated using the whole sample and then with the sample divided into a number of industries. The complete sample results are shown in Table III and the estimated age functions in Figure 3, panels a and b. The estimates are carried out including as control variables a set of time dummies 1991-1998, 18 industry dummies, two dummies related to discrete jumps in the life of firms which may potentially influence all their activity (merger, scission), a set of 6 size dummies, ${ }^{5}$ and the dummy characterising the observations of exiting firms.

Let us comment in the first place on the results obtained with the whole sample. On the one hand, controls give sensible results. Let us explain them with some detail. Time dummies reflect the absence of serious industry economic cycle effects. Time dummy coefficients are small and scarcely significant with a few exceptions, and the strong downturn which Spanish industry registered in 1993 is not reflected in the data. The only noticeable effect is some small transitory slowdown of the innovation propensity which can be attributed to the 1995-1996 pause in economic growth, affecting first the introduction of product innovations and then process innovations. The impact of the firm life events (merger, scission) also turns out to be unimportant. We thus reach the inevitable conclusion that innovation appears to be a rather stable activity, whose level is determined by considerations other than those that are cyclical or episodic.

Secondly, the probability of introducing innovations varies considerably across industries. Recall that industry coefficients give the industry deviations from the average probability as shown by the $\theta(\tau)$ function. Roughly, firms in half of the industries do not diverge significantly from average propensity both in process and product innovations, but firms in the other half show remarkable differences. These differences make sense: Electrical and electronic goods is an industry in which firms show an above-average probability of introducing both product and process innovations; Non-metallic minerals and Food industries are industries in which firms clearly show a below-average probability of introducing all kinds of innovations; Metal Products and Vehicles, cars and motors are industries in which firms tend to show an above-average propensity of introducing process innovations and a below-average probability of introducing product innovations, and Industrial and agricultural machinery is an industry in which firms are characterised by just the opposite.

The range of industry differences in the probability of introducing process innovations amounts to 18 percentage points, and in the probability of product innovation it reaches 27 percentage points. It then seems clear that the different industries' technological opportunities heavily influence the propensity to introduce innovations, and this influence is deeper on product innovation than on process innovation activity. But, as regression results show, the highest variations in probability 
TABLE III

Results from the estimation of model $P(y=1 \mid x, \tau)=x \beta+\theta(\tau)$

Sample period: 1991-1998

\begin{tabular}{|c|c|c|c|c|}
\hline \multirow[t]{2}{*}{ Explanatory variables } & \multicolumn{2}{|c|}{$\begin{array}{l}\text { Dependent variable: } \\
\text { Dummy of process innovation }\end{array}$} & \multicolumn{2}{|c|}{$\begin{array}{l}\text { Dependent variable: } \\
\text { Dummy of product innovatior }\end{array}$} \\
\hline & Coefficient & $t$-ratio ${ }^{\mathrm{a}}$ & Coefficient & $t$-ratio \\
\hline \multicolumn{5}{|l|}{ Time dummies ${ }^{\mathrm{b}}$} \\
\hline 91 & 0.012 & $(1.1)$ & 0.003 & $(0.3)$ \\
\hline 92 & -0.013 & $(-1.3)$ & 0.008 & $(0.9)$ \\
\hline 93 & 0.006 & $(0.6)$ & 0.005 & $(0.6)$ \\
\hline 94 & 0.016 & $(1.4)$ & 0.009 & $(1.1)$ \\
\hline 95 & -0.007 & $(-0.7)$ & -0.017 & $(-2.2)$ \\
\hline 96 & -0.027 & $(-2.7)$ & -0.008 & $(-1.0)$ \\
\hline 97 & -0.012 & $(-1.3)$ & 0.000 & $(0.0)$ \\
\hline 98 & 0.025 & $(2.4)$ & 0.000 & $(0.0)$ \\
\hline \multicolumn{5}{|l|}{ Industry dummies ${ }^{\mathrm{b}}$} \\
\hline Ferrous and non-ferrous metals & 0.032 & $(0.9)$ & -0.056 & $(-1.2)$ \\
\hline Non-metallic minerals & -0.060 & $(-2.8)$ & -0.066 & $(-2.6)$ \\
\hline Chemical products & 0.021 & $(0.8)$ & 0.045 & $(1.5)$ \\
\hline Metal products & 0.026 & $(1.1)$ & -0.062 & $(-3.2)$ \\
\hline Industrial and agricultural mach. & -0.039 & $(-1.5)$ & 0.122 & $(3.4)$ \\
\hline Office and data processing $\mathrm{m}$. & -0.048 & $(-0.6)$ & 0.027 & $(0.4)$ \\
\hline Electrical and electronic goods & 0.068 & $(2.5)$ & 0.145 & (4.4) \\
\hline Vehicles, cars and motors & 0.092 & $(2.7)$ & -0.038 & $(-1.2)$ \\
\hline Other transport equipment & 0.114 & $(2.4)$ & 0.078 & $(1.4)$ \\
\hline Meat and preserved meat & -0.044 & $(-1.4)$ & -0.101 & $(-3.6)$ \\
\hline Food and tobacco & -0.066 & $(-3.4)$ & -0.071 & $(-4.3)$ \\
\hline Beverages & -0.005 & $(-0.1)$ & -0.006 & $(-0.1)$ \\
\hline Textile and clothing & -0.060 & $(-3.1)$ & -0.034 & $(-1.5)$ \\
\hline Leather and shoes & -0.065 & $(-2.3)$ & -0.001 & $(0.0)$ \\
\hline Timber and furniture & -0.048 & $(-2.2)$ & 0.022 & $(0.8)$ \\
\hline Paper and printing products & 0.007 & $(0.3)$ & -0.128 & $(-7.2)$ \\
\hline Rubber and plastic products & 0.067 & $(2.2)$ & 0.021 & $(0.7)$ \\
\hline Other manufacturing products & 0.010 & $(0.2)$ & 0.105 & $(2.1)$ \\
\hline \multicolumn{5}{|l|}{ Size dummies (no. of workers) ${ }^{b}$} \\
\hline Up to 20 & -0.170 & $(-13.7)$ & -0.119 & $(-9.4)$ \\
\hline From 21 to 50 & -0.090 & $(-6.4)$ & -0.067 & $(-4.8)$ \\
\hline From 51 to 100 & -0.048 & $(-2.1)$ & -0.044 & $(-2.1)$ \\
\hline From 101 to 200 & 0.006 & $(0.3)$ & 0.018 & $(0.9)$ \\
\hline From 201 to 500 & 0.099 & $(6.2)$ & 0.060 & $(3.8)$ \\
\hline More than 500 & 0.203 & $(9.1)$ & 0.152 & $(6.6)$ \\
\hline \multicolumn{5}{|l|}{ Event dummies } \\
\hline Merger & -0.015 & $(-0.3)$ & 0.044 & $(1.0)$ \\
\hline Scission & -0.031 & $(-0.7)$ & 0.050 & $(1.0)$ \\
\hline Exiting firm dummy & -0.111 & $(-5.6)$ & -0.037 & $(-1.5)$ \\
\hline \multicolumn{5}{|l|}{ Age function: see Figure 2} \\
\hline Sigma squared & 0.208 & & 0.182 & \\
\hline No. of firms & 2,356 & & 2,356 & \\
\hline No. of observations & 10,735 & & 10,735 & \\
\hline
\end{tabular}

a Robust standard errors.

${ }^{\mathrm{b}}$ Dummy coefficients constrained to add up to zero. 
Panel a: Process innovation

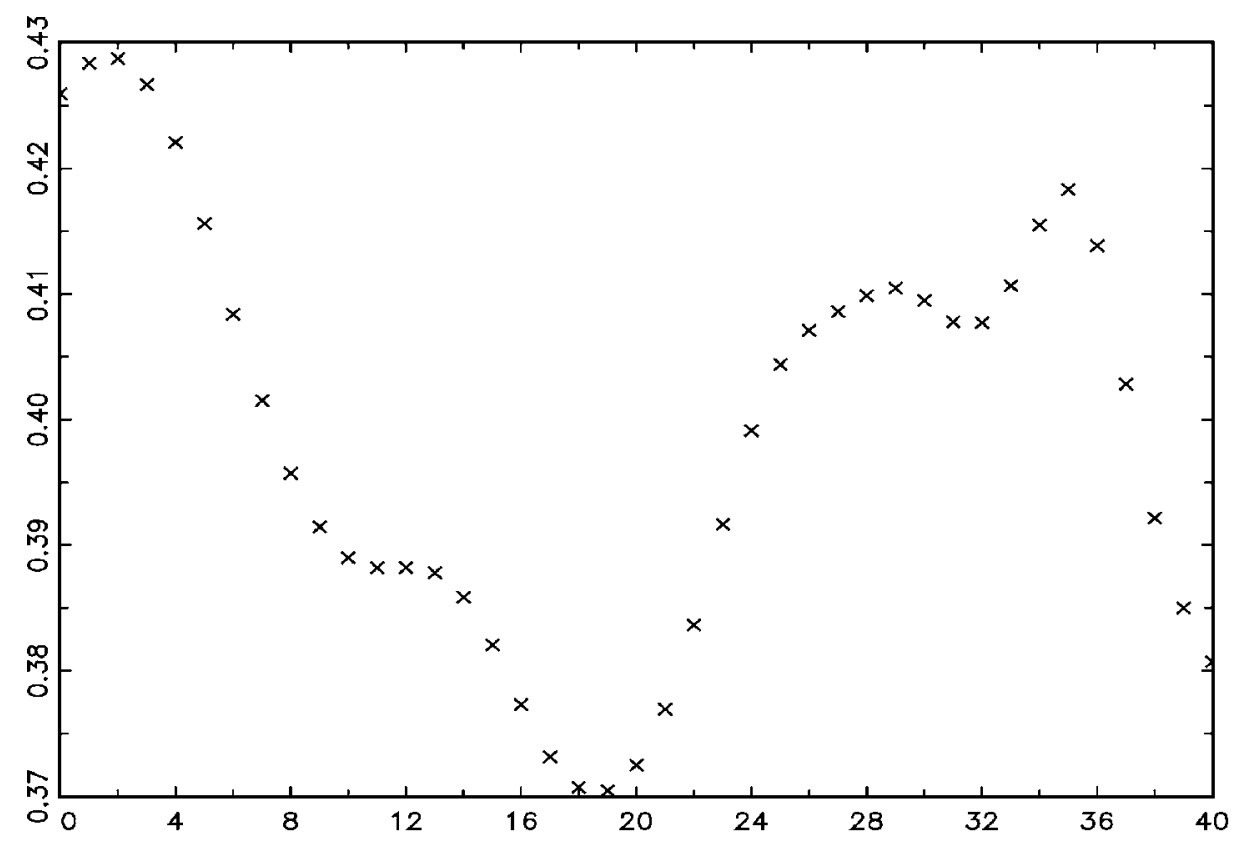

Panel b: Product innovation

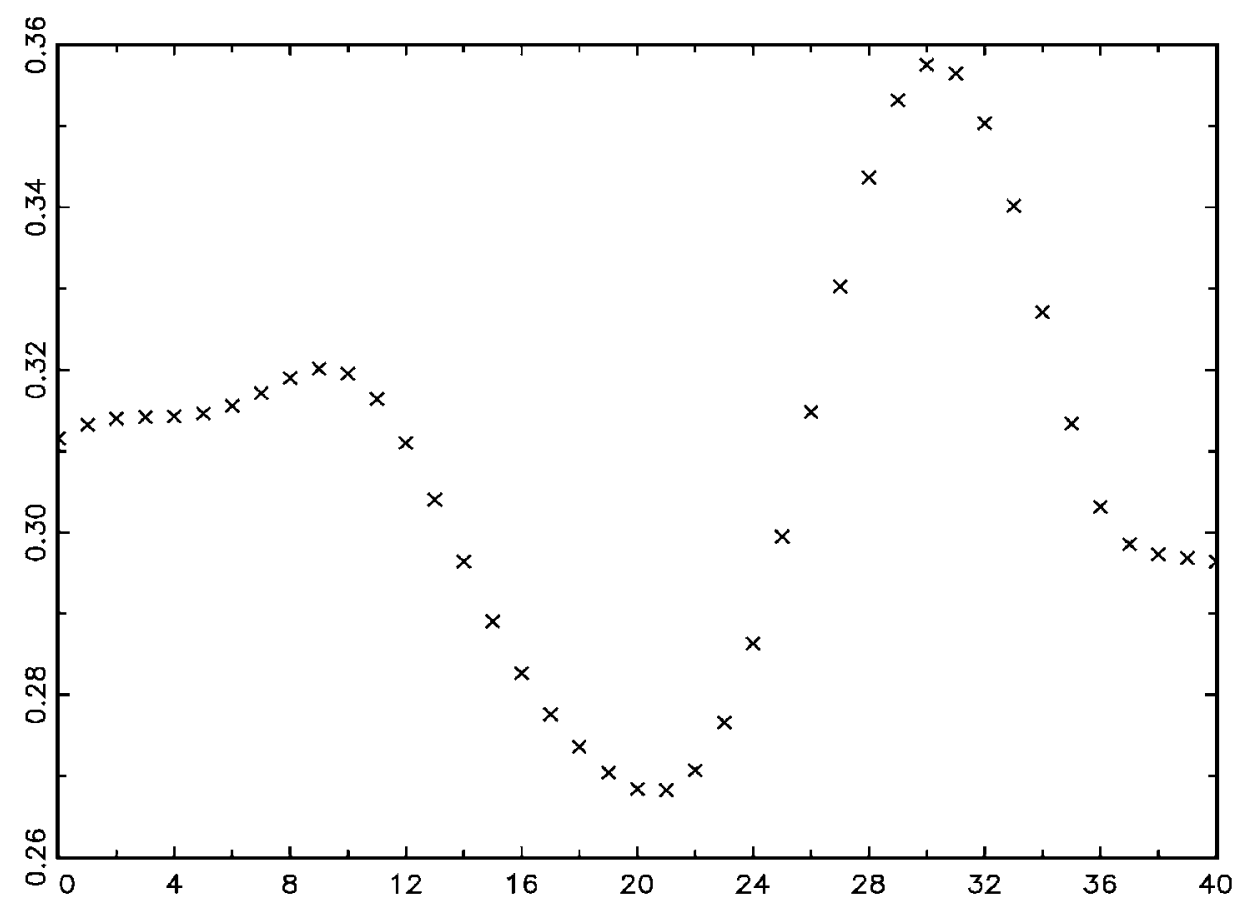

Figure 3. The probability of innovation as a function of age (the $\theta(\tau)$ function) (Values of the function $\theta(\tau)$, estimated with semiparametric techniques, against age). 
results show, the highest variations in probability are linked to size. Let us comment on this.

Innovation is strikingly related in a systematic way to size. ${ }^{6}$ The difference in the probability of introducing innovations between the smallest firms (20 or fewer workers) and the biggest ones (more than 500 workers) amounts to 37 percentage points in the process innovation regression and 27 percentage points in the product innovation regression. In both cases probability increases monotonically with size. This clearly shows that small size is associated by itself to less innovation, and hence suggests that small size per se tends to hinder innovation, probably due to the fixed character of most innovative expenditures. Small entering firms must be regarded therefore as having extra capabilities which outweigh the size handicap.

The regression controls results also ultimately show that exit from the market is clearly associated with a poor relative innovative performance. Firms observed leaving the market during the period show 10 percentage points of difference in their probability of process innovation with respect to the average probability in their industries and sizes, and some (less significant) percentage points of difference in their probability of product innovation. It seems that not being able to get enough cost reductions through process innovations in the first years of life was a crucial motive for having to leave the market, while this would not be the case for the firms which don't obtain enough product innovations (firms can perhaps stay in the market relying on their standard products).

On the other hand, the semiparametric estimates of the probability of introducing process and product innovations as a function of age are plausible and give interesting insights. Some comments are in order. Firstly, the process and product functions maintain a rough similarity which suggests that the introduction of both kinds of innovations over the firms' ages follows the same basic determinants. Notice, however, the lower average frequency of product innovations.

Secondly, probability changes over the life of surviving firms are important, but they clearly contribute less to the heterogeneity of the probabilities than the firms' activity or size. The range of probability variation for reasons of age amounts to $7-8$ percentage points.
Thirdly, the impact of age is highly non-linear. As such, it must be noted that it could not have been assessed by a linear specification. When one conventionally introduces the variable age (in years) in standard regressions of the process and product dummies, specified otherwise as the regressions we are reporting, results do not change very much but the coefficients on age are small and non-significant.

Fourthly, this nonlinearity shows that the evolution of innovative behaviour across ages is complex. On the one hand, entering firms present on average a high probability of innovating, slowly attenuated over the post-entry period of life (continuously in the case of process innovation, decelerating after the ninth year in the case of product innovation), until the firm reaches 18-20 years in the market. On the other, the oldest firms in industry tend to show somewhat lower probabilities of introducing innovations than entrants in their first years. But firms above intermediate ages (between 20-36 years in the market) appear almost as active in process innovations as entering firms and even more in product innovations.

It seems a likely picture, consistent in general terms with the theoretical remarks established in Section 2. The interpretation of our results would be that effectively entering firms and firms of the youngest cohorts are, conditional on the peculiarities of their activity and size, prone to innovate more, and that the oldest ones propend to innovate less than entrants, but also that this is a good forecast only with respect to the firms which have entered the market within the last 18-20 years and for the firms which entered 36 or more years ago. Many firms aged 20 to 36 years seem to remain highly active in innovation, representing the superb performance of the firms which have survived in the markets for more than 20 years of selection. This is especially likely given that the firms which stopped activity are associated with lower levels of propensity to innovate. An alternative explanation would be that these firms belong to some special markets, with an aboveaverage propensity to innovate, not controlled for enough by our rough activity dummies.

The results by industry are shown in Tables IV and $\mathrm{V}$, and a sample of the estimated age functions is shown in Figure 4. In arranging the sample by industries, the 18 sectors are converted into only 
TABLE IV

Selected coefficients and statistics from industry estimates of model $P(y=1 \mid x, \tau)=x \beta+\theta(\tau)$

Dependent variable: Dummy of process innovation

\begin{tabular}{|c|c|c|c|c|c|c|c|c|c|c|}
\hline \multirow{3}{*}{$\begin{array}{l}\text { Explanatory variables }^{\mathrm{a}} \\
\text { Up to } 200 \text { workers } \\
\text { More than } 200 \text { workers }\end{array}$} & \multicolumn{2}{|c|}{$\begin{array}{l}\text { 1. Ferrous and } \\
\text { non-ferrous metals } \\
\text { and metal products }\end{array}$} & \multicolumn{2}{|c|}{$\begin{array}{l}\text { 2. Non-metallic } \\
\text { minerals }\end{array}$} & \multicolumn{2}{|c|}{$\begin{array}{l}\text { 3. Chemical } \\
\text { products }\end{array}$} & \multicolumn{2}{|c|}{$\begin{array}{l}\text { 4. Industrial and } \\
\text { agricultural } \\
\text { machinery }\end{array}$} & \multicolumn{2}{|c|}{$\begin{array}{l}\text { 5. Office and data- } \\
\text { processing machines } \\
\text { and electrical goods }\end{array}$} \\
\hline & -0.108 & $(-4.0)$ & -0.078 & $(-2.6)$ & -0.091 & $(-4.3)$ & -0.113 & $(-3.5)$ & -0.113 & $(-4.2)$ \\
\hline & 0.108 & $(4.0)$ & 0.078 & $(2.6)$ & 0.091 & $(4.3)$ & 0.113 & $(3.5)$ & 0.113 & $(4.2)$ \\
\hline Exiting firm dummy & -0.226 & $(-4.6)$ & -0.075 & $(-1.0)$ & -0.189 & $(-2.1)$ & -0.274 & $(-7.7)$ & 0.060 & $(0.6)$ \\
\hline \multicolumn{11}{|c|}{ Age function: see Figure 3} \\
\hline Sigma squared & \multicolumn{2}{|c|}{0.226} & \multicolumn{2}{|c|}{0.198} & \multicolumn{2}{|c|}{0.235} & \multicolumn{2}{|c|}{0.193} & \multicolumn{2}{|c|}{0.235} \\
\hline No. of firms & \multicolumn{2}{|c|}{325} & \multicolumn{2}{|c|}{153} & \multicolumn{2}{|c|}{305} & \multicolumn{2}{|c|}{141} & \multicolumn{2}{|c|}{219} \\
\hline No. of observations & \multicolumn{2}{|c|}{1321} & \multicolumn{2}{|c|}{752} & & & \multicolumn{2}{|c|}{587} & \multicolumn{2}{|c|}{924} \\
\hline Explanatory variables & \multicolumn{2}{|c|}{$\begin{array}{l}\text { 6. Transport } \\
\text { equipment }\end{array}$} & \multicolumn{2}{|c|}{$\begin{array}{l}\text { 7. Food, drink } \\
\text { and tobacco }\end{array}$} & \multicolumn{2}{|c|}{$\begin{array}{l}\text { 8. Textile, leather } \\
\text { and shoes }\end{array}$} & \multicolumn{2}{|c|}{$\begin{array}{l}\text { 9. Timber and } \\
\text { furniture }\end{array}$} & \multicolumn{2}{|c|}{$\begin{array}{l}\text { 10. Paper and } \\
\text { printing products }\end{array}$} \\
\hline Up to 200 workers & -0.140 & $(-4.8)$ & -0.115 & $(-5.7)$ & -0.094 & $(-3.2)$ & -0.206 & $(-3.2)$ & -0.089 & $(-2.5)$ \\
\hline More than 200 workers & 0.140 & $(4.8)$ & 0.115 & $(5.7)$ & 0.094 & $(3.2)$ & 0.206 & $(3.2)$ & 0.089 & $(2.5)$ \\
\hline Exiting firm dummy & -0.196 & $(-1.4)$ & -0.098 & $(-2.1)$ & -0.136 & $(-4.7)$ & -0.075 & $(-1.5)$ & -0.143 & $(-1.7)$ \\
\hline \multicolumn{11}{|l|}{ Age function: see Figure 3} \\
\hline Sigma squared & \multicolumn{2}{|c|}{0.229} & \multicolumn{2}{|c|}{0.191} & \multicolumn{2}{|c|}{0.182} & \multicolumn{2}{|c|}{0.171} & \multicolumn{2}{|c|}{0.214} \\
\hline No. of firms & \multirow{2}{*}{\multicolumn{2}{|c|}{$\begin{array}{l}156 \\
704\end{array}$}} & \multicolumn{2}{|c|}{356} & \multicolumn{2}{|c|}{361} & \multicolumn{2}{|c|}{157} & & \\
\hline No. of observations & & & & & & & & 44 & & \\
\hline
\end{tabular}

${ }^{a}$ Estimates also include time dummies and the merger and scission variables.

ten to preserve enough sample size for independent estimations. ${ }^{7}$ Industry regressions include the time and merger/scission dummies, size dummies and the exiting firm dummy. Size dummies are reduced to only two in order to simplify things (firms with 200 or fewer workers and firms with more than 200 workers). To save space, in these regressions only the coefficients and $t$-ratios corresponding to the key variables are reported.

Selected results from the regressions by industries are presented in Tables IV and V. They add some interesting insights. Firstly, although not shown in the table, they confirm the presence of no economic cycle effects in the probability of innovation. Secondly, size has a considerable influence on the probability of innovation within each considered industry, with the three interesting exceptions of product innovation in three specific sectors (Industrial and agricultural machinery; Textile, leather and shoes and Timber and furniture). The difference between the probability of introducing innovations by the firms with fewer than 200 workers and the firms with more than this number is about 20 percentage points in process innovations (reaching a peak of 40 percentage points in the Timber and furniture industry), and somewhat less in product innovation (where 20 percentage points tends to be the maximum difference). Thirdly, exit tends to be associated sector to sector with a poor pre-exit process innovation performance (with only one exception), but this is only the case for the Textile, leather and shoes sector in product innovations.

The probabilities of process and product innovation as a function of age, once depicted for each sector, confirm the prevalence of the general traits 
TABLE V

Selected coefficients and statistics from industry estimates of model $P(y=1 \mid x, \tau)=x \beta+\theta(\tau)$

Dependent variable: Dummy of product innovation

\begin{tabular}{|c|c|c|c|c|c|c|c|c|c|c|}
\hline \multirow{3}{*}{$\begin{array}{l}\text { Explanatory variables }{ }^{\mathrm{a}} \\
\text { Up to } 200 \text { workers } \\
\text { More than } 200 \text { workers }\end{array}$} & \multicolumn{2}{|c|}{$\begin{array}{l}\text { 1. Ferrous and } \\
\text { non-ferrous metals } \\
\text { and metal products }\end{array}$} & \multicolumn{2}{|c|}{$\begin{array}{l}\text { 2. Non-metallic } \\
\text { minerals }\end{array}$} & \multicolumn{2}{|c|}{$\begin{array}{l}\text { 3. Chemical } \\
\text { products }\end{array}$} & \multicolumn{2}{|c|}{$\begin{array}{l}\text { 4. Industrial and } \\
\text { agricultural } \\
\text { machinery }\end{array}$} & \multicolumn{2}{|c|}{$\begin{array}{l}\text { 5. Office and data- } \\
\text { processing machines } \\
\text { and electrical goods }\end{array}$} \\
\hline & -0.069 & $(-2.9)$ & -0.074 & $(-2.8)$ & -0.051 & $(-2.3)$ & -0.033 & $(-0.8)$ & -0.061 & $(-1.9)$ \\
\hline & 0.069 & $(2.9)$ & 0.074 & $(2.8)$ & 0.051 & $(2.3)$ & 0.033 & $(0.8)$ & 0.061 & $(1.9)$ \\
\hline Exiting firm dummy & -0.044 & $(-0.9)$ & -0.014 & $(-0.3)$ & -0.002 & $(0.0)$ & -0.113 & $(-1.1)$ & 0.039 & $(0.4)$ \\
\hline \multicolumn{11}{|c|}{ Age function: see Figure 3} \\
\hline Sigma squared & \multicolumn{2}{|c|}{0.159} & \multicolumn{2}{|c|}{0.159} & \multicolumn{2}{|c|}{0.216} & \multicolumn{2}{|c|}{0.232} & \multicolumn{2}{|c|}{0.240} \\
\hline No. of firms & \multicolumn{2}{|c|}{325} & \multicolumn{2}{|c|}{153} & \multicolumn{2}{|c|}{305} & \multicolumn{2}{|c|}{141} & \multicolumn{2}{|c|}{219} \\
\hline No. of observations & \multicolumn{2}{|c|}{1321} & \multicolumn{2}{|c|}{752} & & & \multicolumn{2}{|c|}{587} & \multicolumn{2}{|c|}{924} \\
\hline Explanatory variables & \multicolumn{2}{|c|}{$\begin{array}{l}\text { 6. Transport } \\
\text { equipment }\end{array}$} & \multicolumn{2}{|c|}{$\begin{array}{l}\text { 7. Food, drink } \\
\text { and tobacco }\end{array}$} & \multicolumn{2}{|c|}{$\begin{array}{l}\text { 8. Textile, leather } \\
\text { and shoes }\end{array}$} & \multicolumn{2}{|c|}{$\begin{array}{l}\text { 9. Timber and } \\
\text { furniture }\end{array}$} & \multicolumn{2}{|c|}{$\begin{array}{l}\text { 10. Paper and } \\
\text { printing products }\end{array}$} \\
\hline Up to 200 workers & -0.097 & $(-3.4)$ & -0.106 & $(-5.8)$ & -0.042 & $(-1.5)$ & -0.086 & $(-1.3)$ & -0.098 & $(-5.1)$ \\
\hline More than 200 workers & 0.097 & $(3.4)$ & 0.106 & $(5.8)$ & 0.042 & $(1.5)$ & 0.086 & $(1.3)$ & 0.098 & $(5.1)$ \\
\hline Exiting firm dummy & 0.018 & $(0.1)$ & -0.031 & $(-0.5)$ & -0.134 & $(-4.7)$ & 0.099 & $(1.0)$ & 0.017 & $(0.2)$ \\
\hline \multicolumn{11}{|c|}{ Age function: see Figure 3} \\
\hline Sigma squared & \multicolumn{2}{|c|}{0.216} & \multicolumn{2}{|c|}{0.155} & \multicolumn{2}{|c|}{0.169} & \multicolumn{2}{|c|}{0.182} & \multicolumn{2}{|c|}{0.111} \\
\hline No. of firms & \multicolumn{2}{|c|}{156} & \multicolumn{2}{|c|}{356} & \multicolumn{2}{|c|}{361} & \multicolumn{2}{|c|}{157} & & \\
\hline No. of observations & & 04 & & & & & & 14 & & \\
\hline
\end{tabular}

${ }^{\text {a }}$ Estimates also include time dummies and the merger and scission variables.

explained above but also reveal significant industry heterogeneity. The smaller number of degrees of freedom, however, make these graphs more volatile (they are more sensitive to particular extreme values) and difficult to interpret. To give an idea of the activity differences involved, three relatively well behaved functions have been selected. They correspond to the activities Transport equipment; Food, drink and tobacco, and Paper and printing.

They firstly illustrate how average probability and its range of variation over the firms' ages varies across activities. Average probability, for example, goes from the 52 percentage points in process innovation in Transport equipment to the 16 percentage points in product innovation in Paper and printing. The ranges of variation are more similar, but they range nonetheless from the important differences between the propensity of young and old firms in process innovation in Paper and printing (16\%) to the smaller differences between propensities of firms at different ages in process innovation in Food, drink and tobacco (6\%).

Age patterns also show some significant differences. Differences lie in the extent to which entering firms are intense innovators in relation to the rest of the firms (more in Paper and printing, less in the other sectors), the particular ages at which intense innovative activity of older firms are localised (25-30 years in some activities and kinds of innovation, but these firms do not show up in others), and the extent to which the oldest firms can be considered less innovative (sometimes this is simply not true: e.g. Food, drink and tobacco). On the other hand, there is even a sector 


\section{Transport equipment}
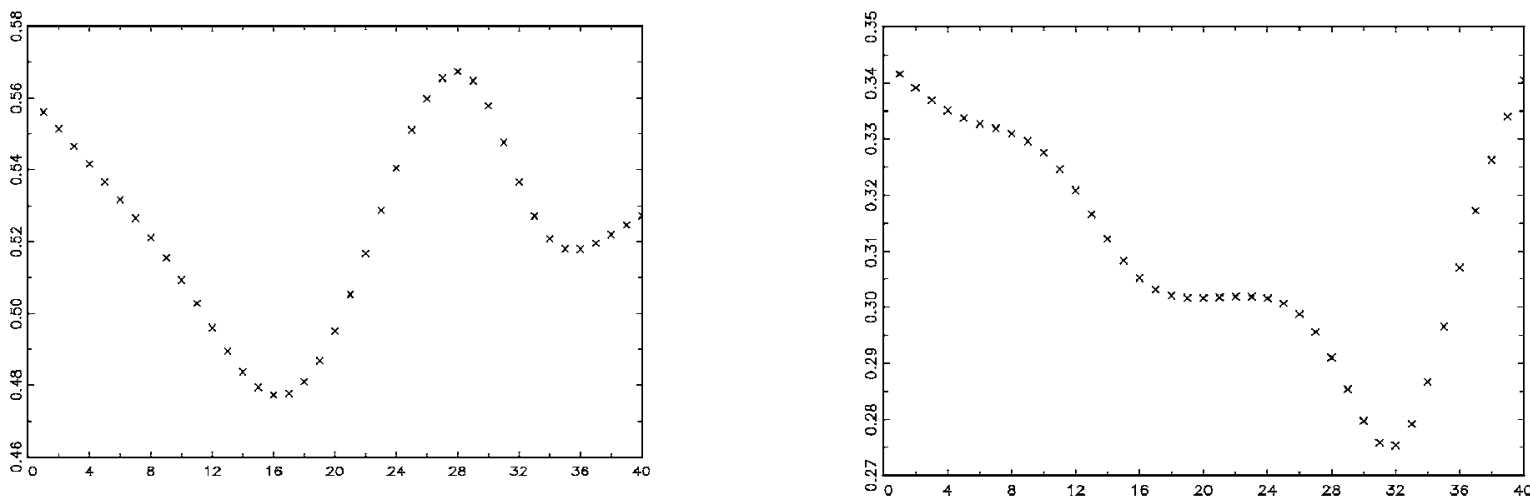

Probability of process innovation

Probability of product innovation

\section{Food, drink and tobacco}

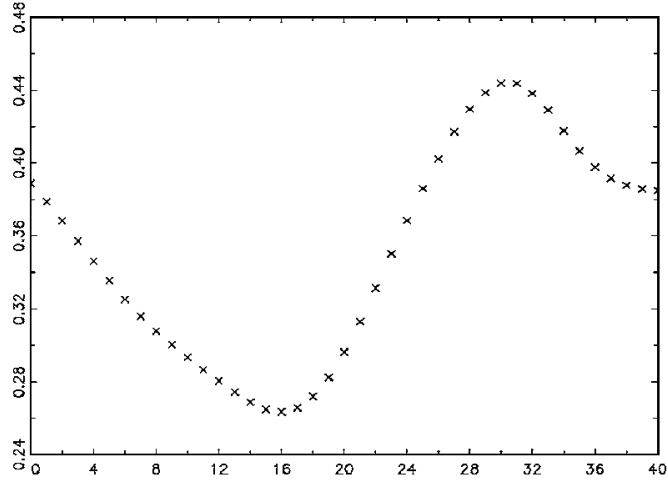

Probability of process innovation

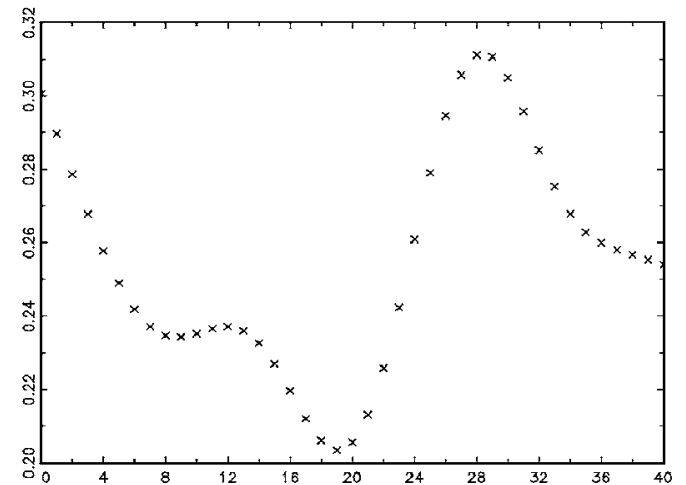

Probability of product innovation

\section{Paper and printing products}

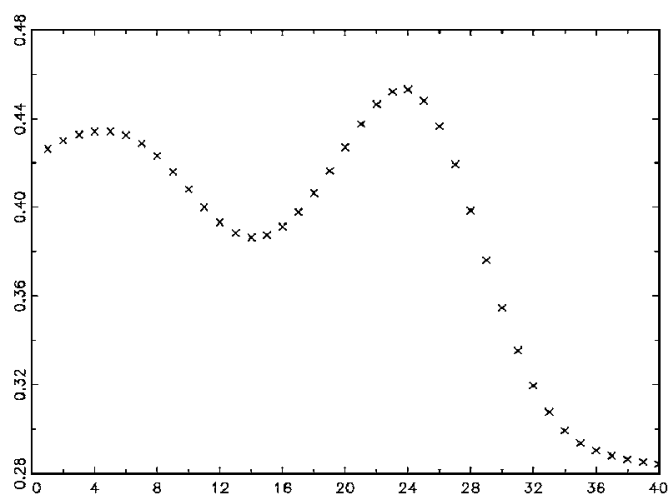

Probability of process innovation

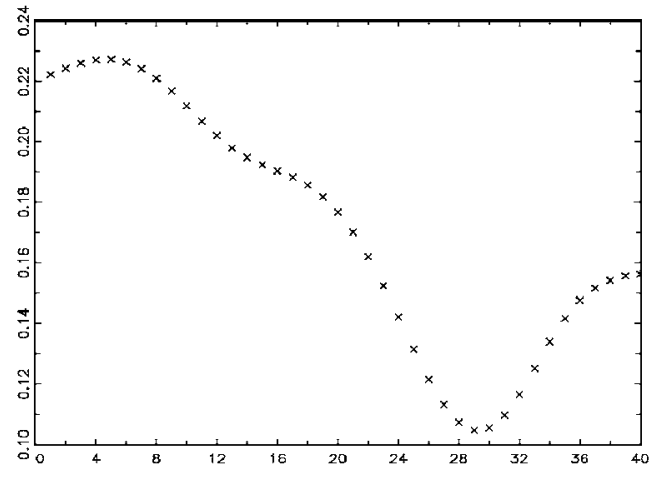

Probability of product innovation

Figure 4. The probability of process and product innovation as a function of age (the $\theta(\tau)$ function by selected industries) (Values of the function $\theta(\tau)$, estimated with semiparametric techniques, against age). 
in which firms follow a completely different pattern: in the Textile, leather and shoes sector, both in process and product innovation, the probability of innovating tends to increase almost monotonically with age.

\section{Conclusion}

This paper has looked at the probability of introducing innovations by manufacturing firms at different stages of their lives. To analyse the evolution of this probability with firms' age, differences in average probability levels across activities and sizes have been controlled for. Results have shown the probability of innovation to be rather stable over time, varying considerably across industries, and increasing monotonically with size.

In this setting, entering firms have been detected to present a high probability of innovating, slowly attenuated over the post-entry period of life. As small size is clearly associated by itself with less innovation, it therefore seems clear that small entering firms must be regarded as having extra capabilities which outweigh the size handicap. At the same time, exit from the market appears to be clearly associated with relatively poor pre-exit innovative performance, mainly in process innovation. On the other hand, the oldest firms in industry tend to show lower probabilities of introducing innovations, at the same time that some firms at more than intermediate ages appear almost as active as, if not more active than, entering firms, especially in product innovations. The specific patterns may, however, show important differences by sectors.

This provides a likely picture, consistent in general terms with many insights advanced by the theoretical literature. Entering firms and firms of the youngest cohorts are, conditional on the peculiarities of their activity and size, prone to innovate more, and the oldest ones propend to innovate less than entrants. But this is a good forecast only with respect to the firms which have entered the market within the last 18-20 years and for the firms which entered 36 or more years ago. Many firms aged 20 to 36 years seem to remain highly active in innovation, probably representing a high performance on the part of the firms which have survived in the markets for more than 20 years of selection, while many other stopped activity after presenting lower levels of propensity to innovate.

\section{Acknowledgements}

We are grateful to David Audretsch, Jose Carlos Fariñas, Xose Mata, Gavin Reid, Marco Vivarelli and the audiences at the Workshop on Demography of Firms and Industries held at the Universitat de Barcelona and the 29th EARIE Conference held at the Universidad Carlos III de Madrid for useful comments. Comments by an anonymous referee have particularly improved the current version. This research has been partially funded by the CICYT project SEC2000-0268. Elena Huergo also acknowledges financial support from the Fundación Empresa Pública.

\section{Appendix: model details and estimation technique}

Our econometric model, dropping subindices for simplicity, therefore has the form

$$
y=x \beta+\theta(\tau)+\varepsilon
$$

where $p=x \beta+\theta(\tau)$. Model (2) is heteroscedastic, with $V(\varepsilon \mid p)$ $=p(1-p)$, but GLS estimation can be easily carried out by weighting variables by $1 / \sqrt{w}=\left[\sum p(1-p) / n p(1-p)\right]^{1 / 2}$.

To estimate (2) we will proceed as follows. Assume that $\tau$ and $\varepsilon$ are uncorrelated,

$$
y-E(y \mid \tau)=[x-E(x \mid \tau)] \beta+\varepsilon
$$

and $\beta$ can be consistently estimated by OLS in (3) provided that the conditional expectation functions $E(y \mid \tau)$ and $E(x \mid \tau)$ are replaced by some nonparametric estimate (we will use the simple kernel regression Nadaraya-Watson estimator; see, for example, Wand and Jones (1995)). With an estimate of $\beta$, we can estimate probabilities by

$$
\hat{p}=\hat{E}(y \mid \tau)+[x-\hat{E}(x \mid \tau)] \hat{\beta}
$$

and replace these probabilities in the above formula to obtain a feasible GLS estimate of $\beta$. Finally, the unknown $\theta(\cdot)$ can be recovered from

$$
\hat{\theta}(\tau)=\hat{E}(y \mid \tau)-\hat{E}(x \mid \tau)] \hat{\beta}_{G L S}
$$

In addition, and despite the GLS theoretical heteroscedasticity correction, we will compute all standard errors by means of the corresponding panel formulas robust to unspecified forms of heterocedasticity and autocorrelation. 


\section{Notes}

1 The main problem with this model is that probability is not constrained to lie in the zero-unit interval. But the use of a specification based on dummy variables and a unique non-dichotomised variable "age," which enters the equation through a flexible functional form, makes this problem negligible.

2 The survey was sponsored by the Spanish Ministry of Industry and carried out at the Programa de Investigaciones Ecónomicas de la Fundación Empresa Pública.

3 Spanish manufacturing consisted of, at the beginning of the 90 s, about 40,000 firms with this size.

4 Our approach to probability estimation is a conditional expectation approach; hence the different weight of the two main subsamples resulting for selective sampling does not constitute a problem (conditional density of $y$ does not change).

5 Employed size intervals, in number of workers, are: up to 20, 21-50, 51-100, 101-200, 201-500, and more than 500.

6 Sample employment size intervals include the following numbers of firms: 712, 555, 179, 203, 488 and 219.

7 The 18 industry dummy variables classification (see Table III) constitutes an adaptation of a standard NACE classification, and the 10 industries classification aggregates it in the following way: $1=1+4,2=2,3=3+17,4=5,5=6+7$, $6=8+9,7=10+11+12,8=13+14,9=15,10=16$. Given the small number of firms and the heterogeneous composition of industry 18 (Other manufacturing), this industry is omitted for independent estimations. Firm numbers at each industry appear in Table IV.

\section{References}

Acs, Z. and D. Audretsch, 1988, 'Innovation in Large and Small Firms: An Empirical Analysis', American Economic Review 78, 678-690.

Acs, Z. and D. Audretsch, 1990, Innovation and Small Firms, MIT Press.
Agarwal, R., 1998, 'Small Firm Survival and Technological Activity', Small Business Economics 11, 215-224.

Audretsch, D., 1995a, Innovation and Industry Evolution, MIT Press.

Audretsch, D., 1995b, 'Innovation, Growth and Survival', International Journal of Industrial Organization 13, 441-447.

Cohen, W. M. and S. Klepper, 1996, 'Firm Size and the Nature of Innovation within Industries: The Case of Process and Product R\&D”, Review of Economics and Statistics 78, 232-243.

Doms, M., T. Dunne and M. Roberts, 1995, 'The Role of Technology Use in the Survival and Growth of Manufacturing Plants', International Journal of Industrial Organization 13, 523-542.

Geroski, P., 1995, 'What Do We Know About Entry?', International Journal of Industrial Organization $\mathbf{1 3}$ 421-440.

Hansen, J. A., 1992, 'Innovation, Firm Size, and Firm Age', Small Business Economics 4, 37-44.

Huergo, E. and J. Jaumandreu, 2002, 'Firms' Age, Process Innovation and Productivity Growth', mimeo.

Klepper, S., 1996, 'Entry, Exit and Innovation Over the Product Life Cycle', American Economic Review 86, 562-583.

McGahan, A. M. and B. S. Silverman, 2001, 'How Does Innovative Activity Change as Industries Mature?', International Journal of Industrial Organization 19, 1141-1160.

Robinson, P. M., 1988, 'Root-n Consistent Semiparametric Regression', Econometrica 56, 97-118.

Speckman, P., 1988, 'Kernel Smoothing in Partially Linear Models', Journal of the Royal Statistical Society, Series B 50, 413-446.

Suits, D., 1984, 'Dummy Variables: Mechanics vs. Interpretation', Review of Economics and Statistics 66, $177-180$

Wand, M. P. and M. C. Jones, 1995, Kernel Smoothing, Chapman \& Hall. 